\title{
Low-Cost Nanocarbon-Based Peroxidases from Graphite and Carbon Fibers
}

\author{
Yan Zeng, Feifan Miao, Zhiyong Zhao, Yuting Zhu, Tao Liu, Rongsheng Chen, Simin Liu, \\ Zaosheng Lv and Feng Liang *
}

The State Key Laboratory of Refractories and Metallurgy, School of Chemistry \& Chemical Engineering, Wuhan University of Science and Technology, Wuhan 430081, China; zengyan@wust.edu.cn (Y.Z.); miaoff@cnnp.com.cn (F.M.); zhaozhiyong@wust.edu.cn (Z.Z.); zhuyt@nanoctr.cn (Y.Z.); liutaowust@163.com (T.L.); chenrs@wust.edu.cn (R.C.); liusimin@wust.edu.cn (S.L.); lvzaosheng@wust.edu.cn (Z.L.)

* Correspondence: feng_liang@whu.edu.cn; Tel.: +86-27-6886-2107

Received: 7 August 2017; Accepted: 6 September 2017; Published: 8 September 2017

\begin{abstract}
A low-cost and facile preparation of water-soluble carbon nanomaterials from commercial available graphite and polypropylene carbon fibers was achieved. $\mathrm{N}$-doped graphene quantum dot was also prepared as a comparable agent. The resultant carbon nanomaterials were characterized by vital techniques such as transmission electron microscopy (TEM), X-ray photoelectron spectroscopy (XPS), UV-vis absorption, Fourier transform infrared (FT-IR) and Raman spectra. The prepared carbon nanomaterials can make hydrogen peroxide degradation produce hydroxyl radicals, thus possess intrinsic peroxidase-like activity for colorimetric and UV-vis absorption detection of hydrogen peroxide. These carbon nanomaterials exhibit excellent sensitivity toward hydrogen peroxide with the limit of detection as low as $0.024 \mathrm{mM}$ (by Carbon nanomaterials- 1 from carbon fibers), $0.0042 \mathrm{mM}$ (by Carbon nanomaterials-2 from graphite) and $0.014 \mathrm{mM}$ (by Carbon nanomaterials-3 from nitrogen doped graphene oxide), respectively. The practical use of these carbon nanomaterials for phenolic compounds removal in aqueous solution is also demonstrated successfully. The extraordinary catalytic performance and low cost of these carbon nanomaterials make them a powerful tool for a wide range of potential applications.
\end{abstract}

Keywords: carbon nanomaterials; nanozyme; peroxidase mimetics; hydrogen peroxide; removal of phenolic compounds

\section{Introduction}

Artificial enzymes as highly stable and low-cost alternatives to natural enzymes hold a great potential and widespread application in biosensor and biomedicine [1]. Metal complexes, supramolecules and biomolecules have been extensively explored to mimic various intrinsic properties of natural enzymes [2]. Recently, nanoparticles (NPs) have attracted increasing attention because of their unique physicochemical properties, such as their comparable size to natural enzymes, high surface area to volume ratio, the presence of a large number of catalytically active sites on their surface and the availability of multifunctional reactive groups for modification and further functionalization $[3,4]$. In 2007, Gao et al. provided the first evidence that inert ferromagnetic nanoparticles have intrinsic peroxidase-like activity [5]. So far, it has been reported over 50 kinds of nanomaterials, which possess intrinsic activity similar to enzymes, such as magnetic nanoparticles, gold nanoparticles, platinum nanoparticles, cerium oxide nanoparticles and carbon nanomaterials [2-8].

Compared with nanomaterials of metals and their oxides, carbon nanomaterials have the advantages of diverse sources, low cost and less toxic in vivo [8-10]. It is also known that carbon nanomaterials can be used as nanotemplates for being functionalized with a wide range of 
(bio)molecules, make it possible their application in different analytical areas or can be implemented in fields of nanomedicine, catalysis, electrocatalysis, electronics, optoelectronics and photovoltaics [11-15]. In 2010, Qu et al. reported the peroxidase-like activity of graphene oxide (GO) and its application to glucose detection [16]. Subsequently, Qu's and other several groups expanded GO to graphene nanocomposites [17], carbon nanotubes (CNTs) [18,19], carbon dots (CDs) [20-22] and graphene quantum dots (GQDs) [23-25] as peroxidase-like catalysts and further prepared GQD-band-aid for wound disinfection [26]. Recently, Chen et al. utilized dopamine as nitrogen source and GO as carbon source to prepare $N$-doped GQDs ( $N$-GQDs) and found $N$-GQDs exhibited the enhanced peroxidase catalytic activity [27].

Although graphene quantum dots (GQDs) and doped GQDs have gained great attention owing to intrinsic peroxidase-like activity for colorimetric and UV-vis absorption detection, GQDs is typically prepared from expensive graphene oxide (GO, the price of $100 \mathrm{mg} \mathrm{GO}$ is about $\$ 15.6$ ) with energy consumed microwave reaction of $12 \mathrm{~h}$ [26,27]. Very recently, we developed a one-pot solvothermal method to prepare carbon dots decorated graphite felt (CDs/GF) electrode, which exhibited excellent wettability and greatly enhanced activity towards vanadium redox couples [28,29]. Herein, we demonstrated the use of low-cost graphite (the price of $100 \mathrm{mg}$ graphite is about $\$ 0.0056$ ) and polypropylene carbon fibers (the price of $100 \mathrm{mg}$ polypropylene carbon fibers is about \$1.37) as carbon source for mixed acid preparation of carbon nanomaterials, and also prepared $\mathrm{N}$-doped GQDs with cheap urea as nitrogen source and GO as carbon source. Three carbon nanomaterials were defined as Carbon nanomaterials-1 (prepared from carbon fibers), Carbon nanomaterials-2 (prepared from graphite), and Carbon nanomaterials-3 (prepared from nitrogen doped graphene oxide) in this manuscript. They were fully characterized by transmission electron microscope (TEM), X-ray photoelectron spectroscopy (XPS), Fourier transform infrared (FT-IR), Zeta potential measurements and Raman spectra. Subsequently, the peroxidase catalytic activities of these carbon nanomaterials were investigated and the catalytic mechanism was discussed. These carbon nanomaterials with peroxidase-like catalytic activity, taking Carbon nanomaterials-2 (prepared from graphite) as an example, were further applied to remove phenolic compounds, the pollutant in water.

\section{Results and Discussion}

\subsection{Synthesis and Characterization of Carbon Nanomaterials}

Three carbon nanomaterials, Carbon nanomaterials-1 (prepared from polypropylene carbon fibers), Carbon nanomaterials-2 (prepared from graphite), and Carbon nanomaterials-3 (nitrogen doped GQDs from GO) were prepared according to the the detail process in the Method section. All carbon nanomaterials were fully characterized by TEM (JEM-2010UHR microscopy, JEOL, Tokyo, Japan), XPS spectroscopy (ESCALAB250Xi, Thermo Fisher Scientific, Beijing, China), FT-IR (VERTEX 70, Bruker, Bremen, Germany), Zeta potential measurements (Zetasizer Nano-ZS ZEN3600 Malvern, Worcestershire, UK) and Raman spectra (INVIA plus Laser Raman Spectrometer, Renishaw, New Mills, UK).

First, the morphology and size of Carbon nanomaterials-1, Carbon nanomaterials-2 and Carbon nanomaterials- 3 were characterized by TEM. The size distribution of Carbon nanomaterials-1, Carbon nanomaterials- 2 and Carbon nanomaterials -3 is in the range of $2-5 \mathrm{~nm}, 3-8 \mathrm{~nm}$ and $1-3 \mathrm{~nm}$ respectively (Figure 1). X-ray photoelectron spectroscopy (XPS) was then used to characterize these carbon nanomaterials. As shown in Figure 2, the dominant graphitic $\mathrm{C} 1$ s peak at $284.8 \mathrm{eV}$ and $\mathrm{O} 1$ s peak at $532 \mathrm{eV}$ were observed for three carbon nanomaterials, and $\mathrm{N} 1$ s peak around $400 \mathrm{eV}$ could be detected for Carbon nanomaterials-3. According to the deconvoluted XPS spectra of $C 1 \mathrm{~s}$ in Figure 3, there were $\mathrm{C}-\mathrm{C}, \mathrm{C}-\mathrm{O}$ and $-\mathrm{COOH}$ on Carbon nanomaterials -1 surface, and $\mathrm{C}=\mathrm{O}$ on Carbon nanomaterials- 2 and Carbon nanomaterials-3 surface. The carbonyl group can act as substrate binding sites [30], which are beneficial to peroxidase like catalytic reaction. This can prove that the catalytic activity of Carbon nanomaterials-2 and Carbon nanomaterials-3 is better than that of Carbon nanomaterials-1. 
The nitrogen element in Carbon nanomaterials- 3 belongs to pyridine type nitrogen, and exists in the form of amino, amide or others (Figure 3). Therefore, all carbon nanomaterials with many hydrophilic functional groups, showed good solubility (up to $1 \mathrm{mg} \cdot \mathrm{mL}^{-1}$ ) in water, and the solution could keep stable for several months at room temperature.
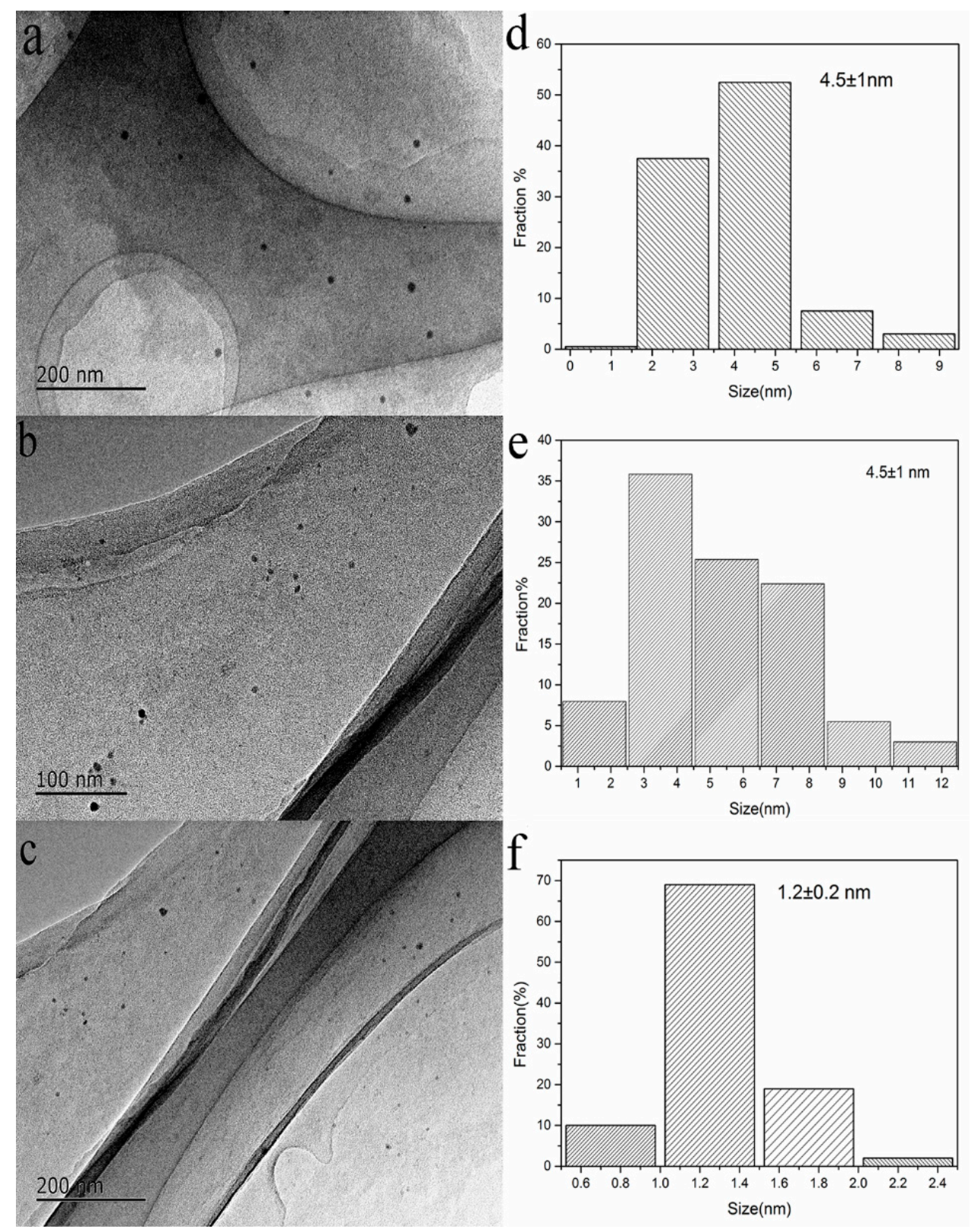

Figure 1. Typical transmission electron microscopy (TEM) images of synthesized carbon nanomaterials in this work: (a) Carbon nanomaterials-1; (b) Carbon nanomaterials-2; (c) Carbon nanomaterials-3; and diameter distribution of carbon nanomaterials; (d) Carbon nanomaterials-1; (e) Carbon nanomaterials-2; (f) Carbon nanomaterials-3. 

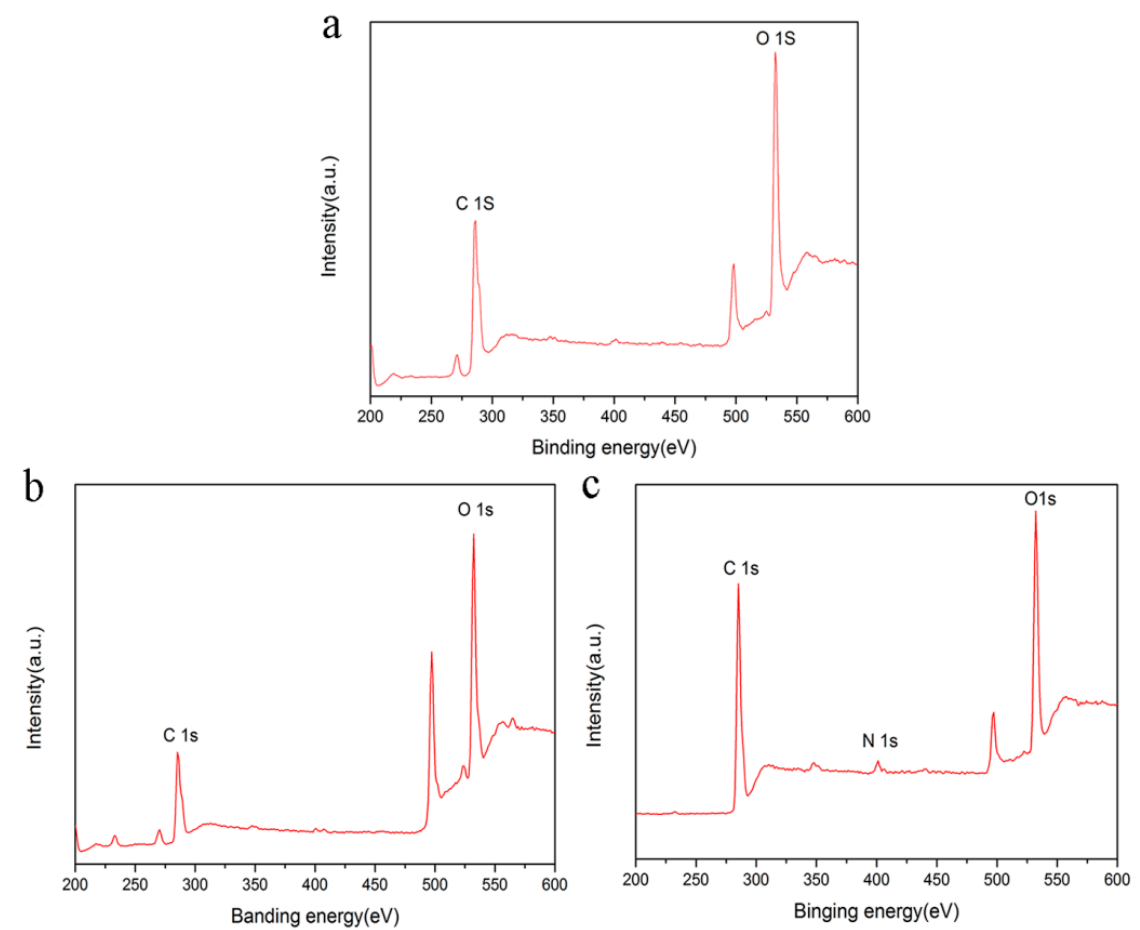

Figure 2. X-ray photoelectron spectroscopy (XPS) survey spectra of the as-synthesized carbon nanomaterials in this work: (a) Carbon nanomaterials-1; (b) Carbon nanomaterials-2; (c) Carbon nanomaterials-3.
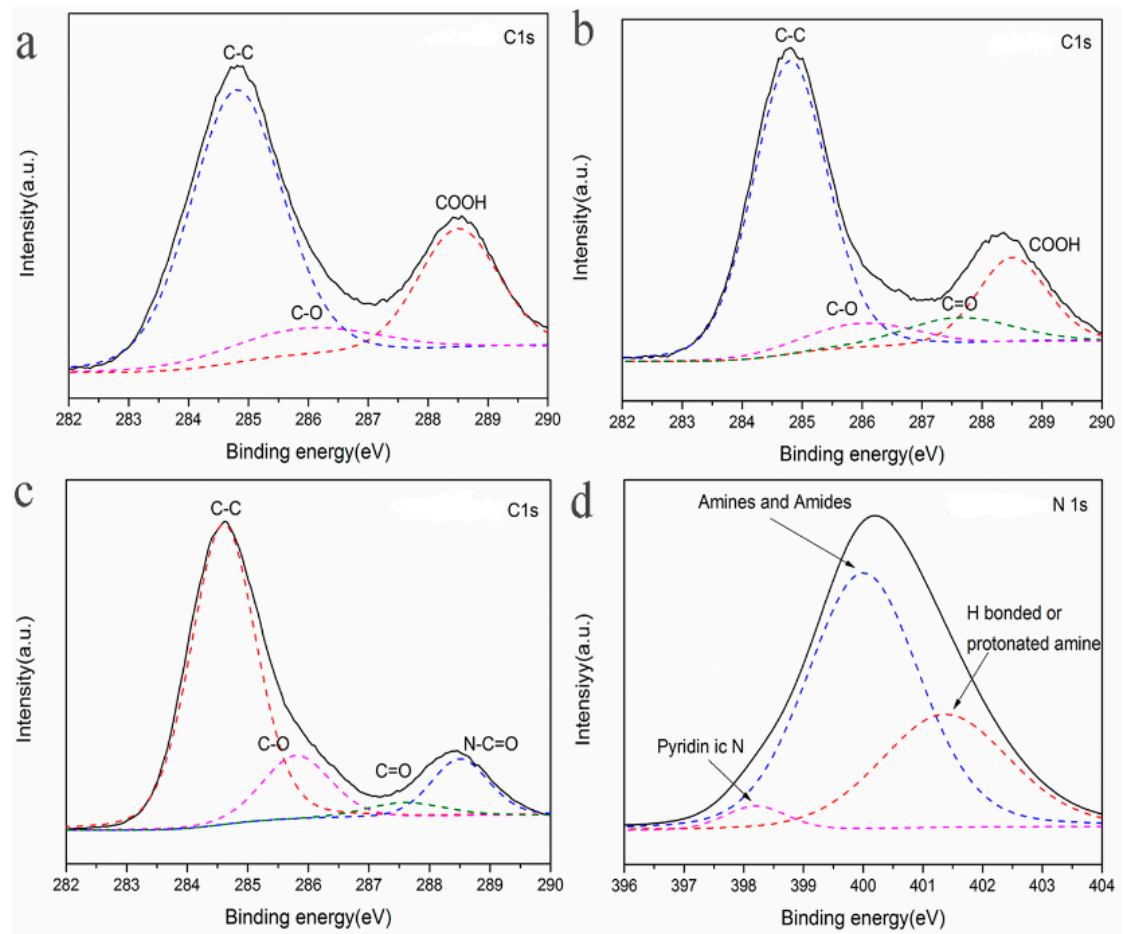

Figure 3. High-resolution XPS spectra of as-synthesized carbon nanomaterials in this work: (a) Carbon nanomaterials-1; (b) Carbon nanomaterials-2; (c,d) Carbon nanomaterials-3.

FT-IR spectroscopy (Figure S1) reveals the existence of O-H in different carbon nanomaterials, which can be seen from the obvious peak at $3650 \mathrm{~cm}^{-1}$. The peak at $3000 \mathrm{~cm}^{-1}$ corresponds to the carboxyl group, and the peak at $1724 \mathrm{~cm}^{-1}$ in the spectrum of Carbon nanomaterials-2 is from the 
carbonyl group. The Raman spectra illustrate the existence of $1350 \mathrm{~cm}^{-1}$ (D) and $1570 \mathrm{~cm}^{-1}$ (G) peaks in different carbon nanomaterials. The $\mathrm{G}$ peak means the $\mathrm{sp}^{2}$ hybrid carbon atom and the $\mathrm{D}$ peak means the $\mathrm{sp}^{3}$ hybrid carbon atom. The value of $I_{D} / I_{G}$ represents the defect layer in the surface and the edge of the carbon material. To be specific, when the value of $I_{D} / I_{G}$ is less than 1 , some functional groups may be introduced into the carbon nanomaterials, thus endowing the nanomaterials with special properties (Figure S2). Among three kinds of carbon nanomaterials, Carbon nanomaterials-3 shows the highest $I_{D} / I_{G}$ value owing to the introduction of nitrogen atoms. Besides, it is noticed that the value of the zeta potential changed a lot when doping nitrogen into the carbon (Figure S3).

\subsection{The Peroxidase Catalytic Activities of Carbon Nanomaterials}

It has been reported that some carbon nanomaterials have the peroxidase-like activity, which can catalyze the oxidation reaction between $\mathrm{H}_{2} \mathrm{O}_{2}$ and 3,3',5,5'-tetramethylbenzidine (TMB), resulting in a blue colored product [16]. In current system, after addition of both $\mathrm{H}_{2} \mathrm{O}_{2}$ and TMB into the Carbon nanomaterials- 2 solution, the solution can change to blue (the tube 4 in Figure $4 a$ ). While only TMB solution or the TMB and $\mathrm{H}_{2} \mathrm{O}_{2}$ solution shows colorless (the tubes 1 and 2 in Figure 4a), and when adding TMB to the Carbon nanomaterials- 2 solution, the solution shows brown due to the intrinsic color of Carbon nanomaterials-2 (the tube 3 in Figure 4a). Meanwhile, Carbon nanomaterials-1 and Carbon nanomaterials-3 have the same results in the color reaction. We noticed that there was no metal catalyst in these carbon nanomaterials from the XPS spectrum as shown in Figure 2. These result indicated that three carbon nanomaterials in our case possessed peroxidase-like catalytic activity. In addition, the profile of the time-dependent absorbance change at $652 \mathrm{~nm}$ (Figure $4 \mathrm{~b}$ ) indicated that the reaction rate and absorbance change greatly increased with increaseing of the Carbon nanomaterials-2 concentration. When the concentration of Carbon nanomaterials- 2 is up to $40 \mu \mathrm{g} \cdot \mathrm{mL}^{-1}$, the reaction rate reaches the maximum value.
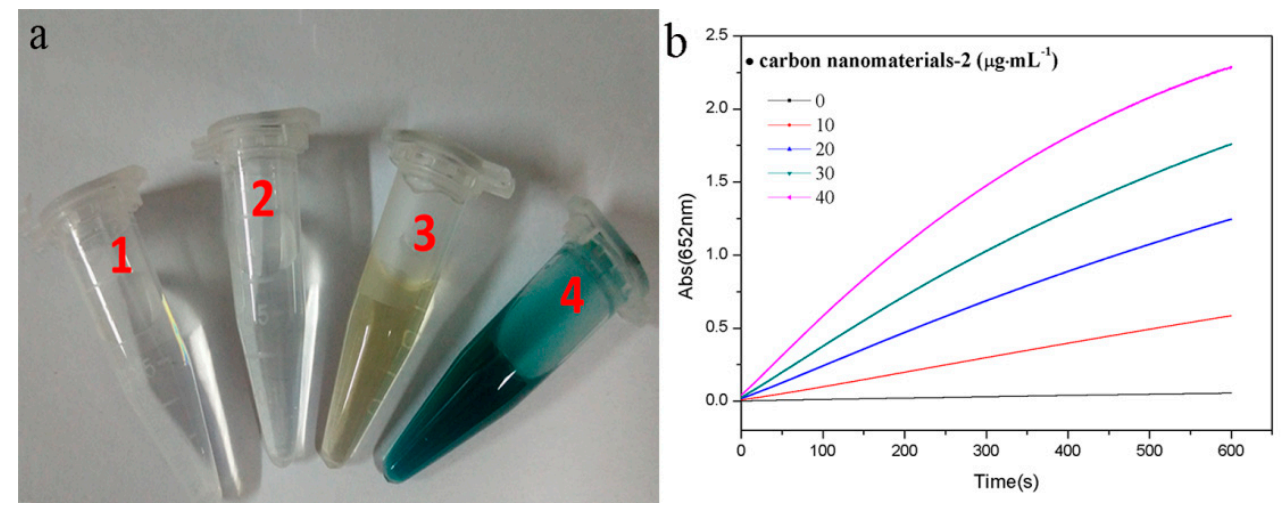

Figure 4. (a) Typical photographs of $1 \mathrm{~mL}$ of $800 \mu \mathrm{M} 3,3^{\prime}, 5,5^{\prime}$-tetramethylbenzidine (TMB) reaction solutions oxidized by Carbon nanomaterials- 2 in the presence of $\mathrm{H}_{2} \mathrm{O}_{2}$ after 5 min incubation at $35^{\circ} \mathrm{C}$ in $25 \mathrm{mM}$ phosphate buffer (pH 4.0): (1) $800 \mu \mathrm{M} \mathrm{TMB}$; (2) $50 \mathrm{mM} \mathrm{H}_{2} \mathrm{O}_{2}$ and $800 \mu \mathrm{M} \mathrm{TMB}$; (3) $800 \mu \mathrm{M}$ $\mathrm{TMB}$ and $40 \mu \mathrm{g} \cdot \mathrm{mL}^{-1}$ Carbon nanomaterials-2; (4) $50 \mathrm{mM} \mathrm{H}_{2} \mathrm{O}_{2}, 800 \mu \mathrm{M}$ TMB and $40 \mu \mathrm{g} \cdot \mathrm{mL}^{-1}$ Carbon nanomaterials-2; (b) The time-dependent absorbance changes at $652 \mathrm{~nm}$ in the absence or presence of Carbon nanomaterials- 2 in $25 \mathrm{mM}$ phosphate buffer ( $\mathrm{pH} 4.0$ ) at $35^{\circ} \mathrm{C}$. The profile of the time-dependent absorbance were acquired with an UV-3600 UV-vis-NIR spectrometer (Shimadzu, Kyoto, Japan).

Typically, the catalytic activity of peroxidase-like carbon nanomaterials mainly depends on the $\mathrm{pH}$ value, temperature and concentration of $\mathrm{H}_{2} \mathrm{O}_{2}$. Figure $\mathrm{S} 4 \mathrm{a}$ shows that the reaction is $\mathrm{pH}$ dependent, and the optimum $\mathrm{pH}$ value is 4.0 , and the catalytic activity can be terminated by the addition of excess acid. As shown in Figure S4b, the temperature could consistantly accelarate the reaction in the tested range. Therefore the optimal temperature is kept at $35{ }^{\circ} \mathrm{C}$, which is very beneficial for practical detection. Figure S4c shows the kinetic behaviors of $\mathrm{H}_{2} \mathrm{O}_{2}$ function system. In the presence of 
fixed carbon nanomaterials, absorbance at $652 \mathrm{~nm}$ increases rapidly before $150 \mathrm{mM}$ of $\mathrm{H}_{2} \mathrm{O}_{2}$ and then increases slightly after $150 \mathrm{mM}$ of $\mathrm{H}_{2} \mathrm{O}_{2}$. The results demonstrate that the catalytic reaction is a $\mathrm{H}_{2} \mathrm{O}_{2}$ concentration-dependent process, and the system could be applied in the determination of $\mathrm{H}_{2} \mathrm{O}_{2}$.

The peroxidase catalytic activities of different carbon nanomaterials were compared in the oxidation reaction between $\mathrm{H}_{2} \mathrm{O}_{2}$ and TMB (Figure S5). The results show that the three kinds of carbon nanomaterials can significantly accelerate the reaction, of which Carbon nanomaterials- 2 and Carbon nanomaterials- 3 have better effects relative to Carbon nanomaterials- 1 . To further compare the catalytic activities of different carbon nanomaterials, state kinetic parameters were examined within an appropriate concentration range of $\mathrm{TMB}$ and $\mathrm{H}_{2} \mathrm{O}_{2}$. In the experiment, the concentration of one substrate is fixed, and the concentration of the other substrate is variable. The initial velocity of the reaction can be obtained by measuring the relationship curve of absorbance at $652 \mathrm{~nm}$ and time. Lineweaver-Burk plot is used to calculate Michaelis Menten constant $\left(K_{\mathrm{m}}\right)$ and maximum reaction rate ( $\left.V_{\max }\right)$ of the three kinds of carbon nanomaterials (Figure S6). Here, the $K_{\mathrm{m}}$ value reveals the binding affinity between enzymes and substrates, and the $V_{\max }$ value reveals the turnover number of enzymes, which reflects their catalytic activity [16].

As shown in Table 1, using TMB as the variable substrate, the $K_{\mathrm{m}}$ value of Carbon nanomaterials- 1 is the highest, so that higher $\mathrm{H}_{2} \mathrm{O}_{2}$ concentration is necessary in order to get better catalytic activity. In contrast, the $K_{\mathrm{m}}$ values of Carbon nanomaterials- 2 and Carbon nanomaterials-3 are very similar and relatively low, indicating that both of them have a good affinity with TMB. On the other hand, the $V_{\max }$ value of Carbon nanomaterials-2 is close to that of Carbon nanomaterials-3, but two times high as that of Carbon nanomaterials- 1 . Using $\mathrm{H}_{2} \mathrm{O}_{2}$ as the variable substrate, the $K_{\mathrm{m}}$ value of Carbon nanomaterials-3 is the lowest, which indicates that Carbon nanomaterials-3 have better affinity with $\mathrm{H}_{2} \mathrm{O}_{2}$ than others. However, Carbon nanomaterials-2 show the largest $V_{\max }$ value among the three kinds of carbon nanomaterials, which probably means more active sites on Carbon nanomaterials-2. It is noticed that the prepared carbon nanomaterials show lower $K_{\mathrm{m}}$ value and higher $V_{\max }$ value, and their $V_{\max }$ value is two orders of magnitude higher than that reported in previous literature [27]. Consequently, the three kinds of carbon nanomaterials have better catalytic activity than those reported in the previous literatures.

Table 1. Michaelis-Menten constant $\left(K_{\mathrm{m}}\right)$ and maximum reaction rate $\left(V_{\max }\right)$ of different carbon nanomaterials in this work and references.

\begin{tabular}{|c|c|c|c|c|}
\hline Catalyst & Substrate Varied & $\begin{array}{c}\text { Substrate Fixed } \\
(\mathrm{mM})\end{array}$ & $\begin{array}{c}K_{\mathrm{m}} \\
(\mathrm{mM})\end{array}$ & $\begin{array}{c}V_{\max } \\
\left(10^{-8} \mathrm{M} \cdot \mathrm{s}^{-1}\right)\end{array}$ \\
\hline Carbon nanomaterials-1 (this work) & \multirow{2}{*}{$\begin{array}{c}\mathrm{TMB}\left(3,3^{\prime}, 5,5^{\prime}-\right. \\
\text { Tetramethylbenzidine }) \\
\mathrm{H}_{2} \mathrm{O}_{2}\end{array}$} & $\mathrm{H}_{2} \mathrm{O}_{2}(25)$ & 2.45 & 155.9 \\
\hline Carbon nanomaterials-1 (this work) & & $\operatorname{TMB}(0.2)$ & 0.01 & 10.31 \\
\hline Carbon nanomaterials-2 (this work) & $\mathrm{TMB}$ & $\mathrm{H}_{2} \mathrm{O}_{2}(5)$ & 1.06 & 337.7 \\
\hline Carbon nanomaterials-2 (this work) & $\mathrm{H}_{2} \mathrm{O}_{2}$ & $\mathrm{TMB}(0.2)$ & 0.001 & 55.13 \\
\hline Carbon nanomaterials-3 (this work) & TMB & $\mathrm{H}_{2} \mathrm{O}_{2}(5)$ & 0.97 & 328.5 \\
\hline Carbon nanomaterials-3 (this work) & $\mathrm{H}_{2} \mathrm{O}_{2}$ & $\mathrm{TMB}(0.2)$ & 0.0006 & 27.69 \\
\hline $\begin{array}{l}N \text {-GQDs ( } N \text {-doped graphene } \\
\text { quantum dots) (Ref. [27]) }\end{array}$ & TMB & $\mathrm{H}_{2} \mathrm{O}_{2}(3.3)$ & 11.2 & 0.38 \\
\hline N-GQDs (Ref. [27]) & $\mathrm{H}_{2} \mathrm{O}_{2}$ & $\operatorname{TMB}(0.3)$ & 0.10 & 0.14 \\
\hline
\end{tabular}

\section{3. $\mathrm{H}_{2} \mathrm{O}_{2}$ Detection Utilizing Carbon Nanomaterials}

Our system could be applied in the determination of $\mathrm{H}_{2} \mathrm{O}_{2}$ because the peroxidase-like activity of carbon nanomaterials is dependent on the concentration of $\mathrm{H}_{2} \mathrm{O}_{2}$. As shown in Figure $5 \mathrm{a}, \mathrm{c}, \mathrm{e}$, the absorbance keep increasing with the increase of $\mathrm{H}_{2} \mathrm{O}_{2}$ concentration and the color reaction is obvious, which may be observed by naked eyes. As can be seen in Figure $5 \mathrm{~b}, \mathrm{~d}, \mathrm{f}$, the absorbance at $652 \mathrm{~nm}$ shows a good linear relationship with the concentration of $\mathrm{H}_{2} \mathrm{O}_{2}$ in the range of 0.02 0.2 $\mathrm{mM}$ when Carbon nanomaterials- 1 and Carbon nanomaterials- 2 are used. In the case of Carbon nanomaterials- 1 , the linear regression equation is $A=0.34 C+0.043$ with a correlation coefficient 
of 0.9937; in the case of Carbon nanomaterials-2, the linear regression equation is $A=1.484 C+0.065$ with a correlation coefficient of 0.9943 . In the case of Carbon nanomaterials-3, as the $\mathrm{H}_{2} \mathrm{O}_{2}$ concentration changes from 0.02 to $0.4 \mathrm{mM}$, the linear regression equation is $A=0.637 \mathrm{C}+0.032$ with a correlation coefficient of 0.9884 . The detection limit of the method using Carbon nanomaterials-1, Carbon nanomaterials-2, Carbon nanomaterials-3 are $0.024 \mathrm{mM}, 0.0042 \mathrm{mM}$ and $0.014 \mathrm{mM}$, respectively. It has been reported that the presence of functional group could affect peroxidase-like activity of carbon nanomaterials [30]. The ketonic carbonyl groups act as the catalytically active sites and the carboxylic groups serve as the substrate-binding sites. The existence of phenol and alcohol groups decreases the catalytic activity of carbon nanomaterials. The Carbon nanomaterials- 2 prepared from natural graphite has better catalytic activity than Carbon nanomaterials-1 prepared from carbon fibers. The possible reason is that the surface of the Carbon nanomaterials-2 contains more ketonic carbonyl groups and carboxylic groups than that of Carbon nanomaterials-1 (Figure 3).


Figure 5. UV-vis absorption spectra and linear calibration plot for $\mathrm{H}_{2} \mathrm{O}_{2}$ detection using (a,b): Carbon nanomaterials-1; (c,d): Carbon nanomaterials-2; (e,f): Carbon nanomaterials-3. The solution of $800 \mu \mathrm{M}$ TMB was treated with $40 \mu \mathrm{g} \cdot \mathrm{mL}^{-1}$ carbon nanomaterials in phosphate buffer $(\mathrm{pH} 4.0)$ at $35{ }^{\circ} \mathrm{C}$. The concentration of $\mathrm{H}_{2} \mathrm{O}_{2}$ was changed from 0 to $16 \mathrm{mM}$. The absorption spectra were acquired with an UV-3600 UV-vis-NIR spectrometer (Shimadzu, Kyoto, Japan). 


\subsection{Catalytic Mechanism of Carbon Nanomaterials}

The peroxidase-like properties of carbon nanomaterials may originate from their catalytic ability, which can make hydrogen peroxide degradation produce hydroxyl radicals $(\bullet \mathrm{OH})[16]$. In this study, fluorescence experiments are carried out to detect $\bullet \mathrm{OH}$ during the reaction. $\bullet \mathrm{OH}$ can be captured by terephthalic acid (TA) as a fluorescence probe and generate 2-hydroxyl terephthalic acid (TAOH), which can emit unique fluorescence at $435 \mathrm{~nm}$ (Figure 6a). As shown in Figure $6 \mathrm{~b}-\mathrm{d}$, three kinds of carbon nanomaterials present the same variation trend in fluorescence intensity after $24 \mathrm{~h}$, and the fluorescence intensity of the solution with TA, $\mathrm{H}_{2} \mathrm{O}_{2}$ and carbon nanomaterials is significantly enhanced. These results prove the presence of $\bullet \mathrm{OH}$ during the interaction between carbon nanomaterials and $\mathrm{H}_{2} \mathrm{O}_{2}$. Similar to peroxidase mimics with iron centers, electron transfer may occur between pairs of different oxidation states of carbon nanomaterials, which can promote their catalytic activity.

a

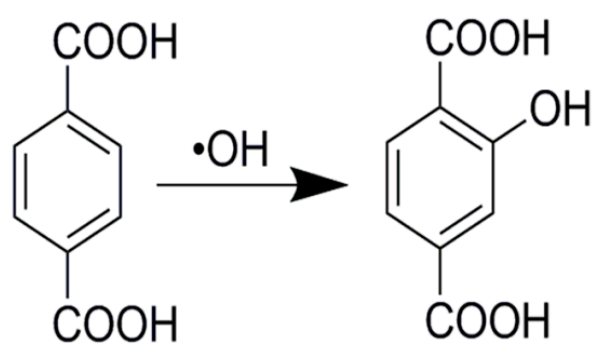

$\lambda_{\mathrm{ex}}=315 \mathrm{~nm}$

$\lambda_{\mathrm{em}}=435 \mathrm{~nm}$

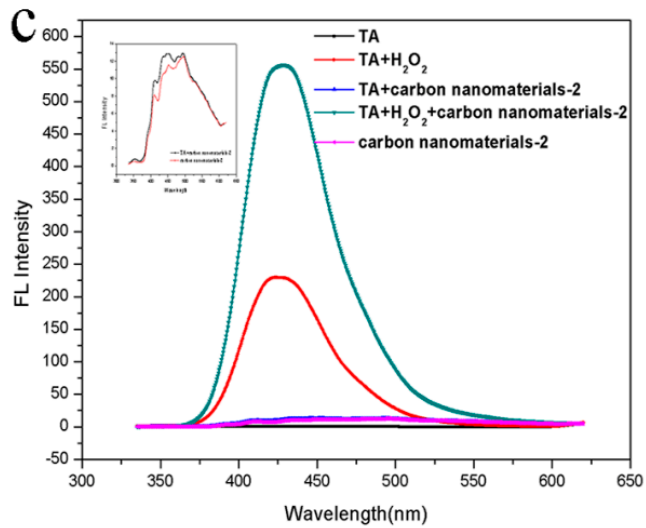

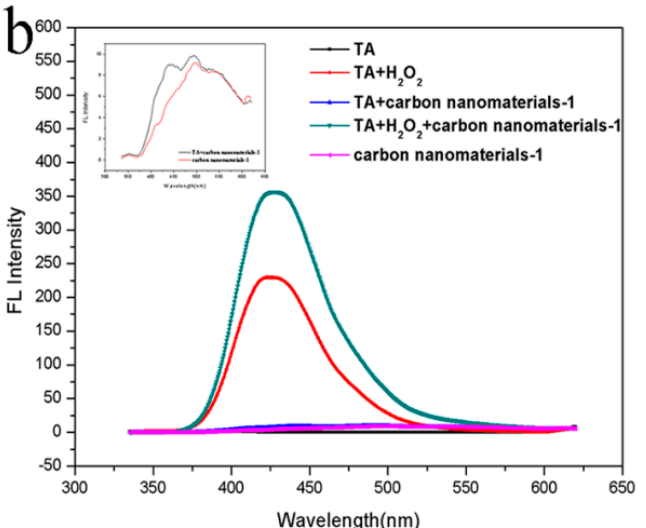

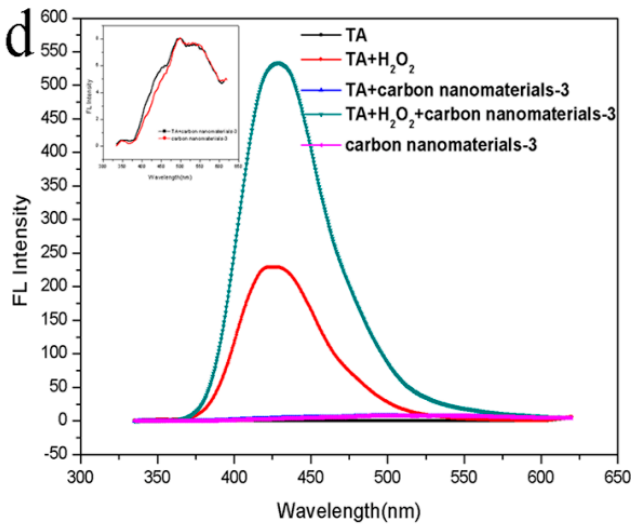

Figure 6. (a) Reaction between hydroxyl radica $\bullet \mathrm{OH}$ and terephthalic acid (TA). Fluorescence spectra of TA with/without $\mathrm{H}_{2} \mathrm{O}_{2}$ treated $24 \mathrm{~h}$ with carbon nanomaterials; (b) Carbon nanomaterials-1; (c) Carbon nanomaterials-2; (d) Carbon nanomaterials-3. In the reaction system, the $\mathrm{TA}, \mathrm{H}_{2} \mathrm{O}_{2}$ and carbon nanomaterials were $0.5 \mathrm{mM}, 1 \mathrm{mM}$, and $20 \mu \mathrm{g} \cdot \mathrm{mL}^{-1}$, respectively. The fluorescence spectra were acquired with a LS55 fluorescence spectrometer (PerkinElmer, Waltham, MA, USA).

\subsection{Phenolic Compounds Removal Utilizing Carbon Nanomaterials}

The removal of phenolic compounds using different carbon nanomaterials as the catalyst in presence of $\mathrm{H}_{2} \mathrm{O}_{2}$ was explored. In a typical procedure [31], $1 \mathrm{mg}$ of carbon nanomaterials was added into $1 \mathrm{~mL}$ of $\mathrm{NaAc}$ buffer $(0.1 \mathrm{M}, \mathrm{pH} 3.5)$ containing $6 \mathrm{mM}$ of phenol and $30 \mathrm{mM}$ of $\mathrm{H}_{2} \mathrm{O}_{2}$, and then incubated at $30^{\circ} \mathrm{C}$ for $24 \mathrm{~h}$. After $24 \mathrm{~h}$ of reaction, the residual phenolic compounds present in the supernatant was measured with potassium ferricyanide and 4-aminoantipyrine, to determin the removal efficiency by measuring the absorbance of the phenol complex at $490 \mathrm{~nm}$ (Figure 7a). It was found that $12.03 \%, 55.7 \%$ and $71.7 \%$ of the phenol were removed by Carbon nanomaterials- 1 , Carbon 
nanomaterials-2 and Carbon nanomaterials-3 (Figure 7b). Carbon nanomaterials-2 was further used to remove homologues of phenol under the same condition. Among tested phenolic compounds, the removal effiency of 2,4-dichlorophenol was $23.64 \%$, the removal effiency of 4-methoxyphenol was $56.35 \%$, the removal effiency of resorcinol was $21.2 \%$.
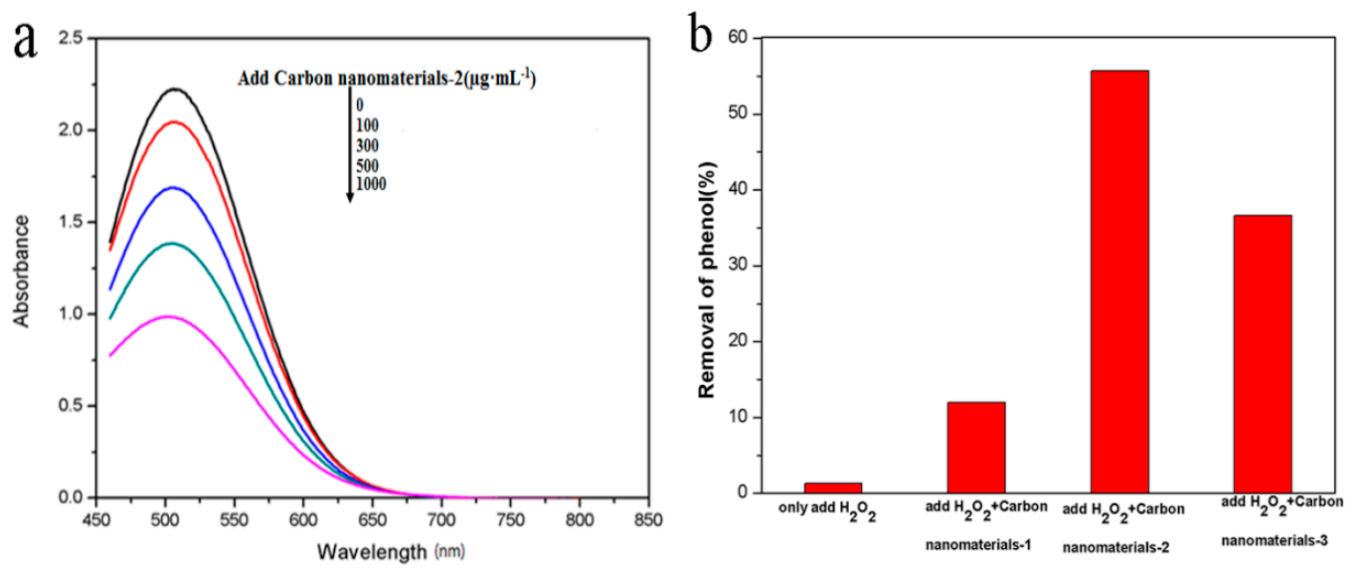

Figure 7. (a) UV-vis absorption spectra of the products obtained by chromogenic reaction of phenol. Different concentrations of Carbon nanomaterials- 2 were added into $1 \mathrm{~mL}$ of NaAc buffer $(0.1 \mathrm{M}$, $\mathrm{pH}$ 3.5) containing $6 \mathrm{mM}$ of phenol and $30 \mathrm{mM}$ of $\mathrm{H}_{2} \mathrm{O}_{2}$, and then incubated at $30^{\circ} \mathrm{C}$ for $24 \mathrm{~h}$. After the residual phenol in these solutions had chromogenic reaction, its absorption curve was determined by an UV-3600 UV-vis-NIR spectrometer (Shimadzu, Kyoto, Japan); (b) Removal efficiency (\%) of phenol when added various carbon nanomaterials.

\section{Materials and Methods}

\subsection{Synthesis of Carbon Nanomaterials-1 and Carbon Nanomaterials-2}

The synthesis details of Carbon nanomaterials-2 were described as follows [23,32]. Commercially available graphite powder or milled carbon fiber powder (300 $\mathrm{mg})$ was added into a mixture of concentrated $\mathrm{H}_{2} \mathrm{SO}_{4}(95 \%, 60 \mathrm{~mL})$ and $\mathrm{HNO}_{3}(65 \%, 20 \mathrm{~mL})$. The suspension was sonicated for $2 \mathrm{~h}$, then refluxed for additional $24 \mathrm{~h}$. Afterwards, the mixture was cooled to room temperature and diluted with deionized water to $800 \mathrm{~mL}$. Successively, the $\mathrm{pH}$ value of the reaction solution was adjusted to 8 with $\mathrm{Na}_{2} \mathrm{CO}_{3}$. After the suspension was concentrated to $50 \mathrm{~mL}$ and filtered to remove the precipitated inorganic salts. The filtrate was collected and further dialyzed in a dialysis bag (3000 molar mass cutoff) for 7 days. Carbon nanomaterials-2 or Carbon nanomaterials-1 powder could be obtained by freeze-drying.

\subsection{Synthesis of Carbon Nanomaterials-3}

Firstly, GO was prepared from graphite by following the method reported by Yan et al. [33] in a typical synthesis. $4 \mathrm{~g}$ of urea was added into $20 \mathrm{~mL}$ of $\mathrm{GO}$ aqueous suspension $\left(1 \mathrm{mg} \cdot \mathrm{mL}^{-1}\right)$, and the mixture was ultra-sonicated for $2 \mathrm{~h}$. Then, $18 \mathrm{~mL}$ mixture was transferred to a Teflon-lined stainless steel autoclave with a volume of $20 \mathrm{~mL}$. The mixture was sealed and heated at $170{ }^{\circ} \mathrm{C}$ for $12 \mathrm{~h}$. The resultant Carbon nanomaterials-3 was filtered, washed and dispersed in water [34].

\section{Conclusions}

In summary, graphite, polypropylene carbon fibers and GO were used as raw materials to synthesize Carbon nanomaterials-2, Carbon nanomaterials-1 and Carbon nanomaterials-3. The peroxidase-like activities of resultant carbon nanomaterials were determined. It was found that carbon nanomaterials had similar properties to natural enzymes, which closely depended on the $\mathrm{pH}$ value, temperature, and the concentration of $\mathrm{H}_{2} \mathrm{O}_{2}$. According to kinetic analysis, Carbon nanomaterials- 3 had the best catalytic 
activity, Carbon nanomaterials-2 showed similar catalytic activity to Carbon nanomaterials-3 and catalytic activity of Carbon nanomaterials- 1 was the lowest. Considering the synthetic process and the cost of raw materials, Carbon nanomaterials-2 synthesized from graphite could function as one kind of ideal substitute for natural enzymes. In addition, these carbon nanomaterials could be used to quantitatively determine the concentration of $\mathrm{H}_{2} \mathrm{O}_{2}$ by using a simple, rapid, highly selective and sensitive colorimetric method. It was also demonstrated that as-obtained three carbon nanomaterials exhibited comparable catalytic efficiency for some phenolic compounds removal.

Supplementary Materials: The following are available online at http:/ /www.mdpi.com/2076-3417/7/9/924/s1, Figure S1: FT-IR Spectrometer of as-synthesized carbon nanomaterials in this work; Figure S2: Raman spectra of as-synthesized carbon nanomaterials in this work; Figure S3: Zeta potential of as-synthesized carbon nanomaterials in this work; Figure S4: Effects of $\mathrm{pH}$ value, temperature and $\mathrm{H}_{2} \mathrm{O}_{2}$ concentrations on the peroxidase catalytic activities of different carbon nanomaterials; Figure S5: The time-dependent absorbance at $652 \mathrm{~nm}$ in the presence of $40 \mu \mathrm{g} \cdot \mathrm{mL}^{-1}$ different carbon nanomaterials; Figure S6: The kinetic behaviors for as-prepared carbon nanomaterials.

Acknowledgments: We acknowledge the financial support from National Natural Science Foundation of China (21372183), Thousand Youth Talents Program, Program for Innovative Teams of Outstanding Young and Middle-aged Researchers in the Higher Education Institutions of Hubei Province (T201702), the Open Funds of the State Key Laboratory of Electroanalytical Chemistry (SKLEAC201609), the Coal Conversion and New Carbon Materials Hubei Key Laboratory (WKDM2015010), and National College Students Innovation and Entrepreneurship Training Program, China (No. 201410488013).

Author Contributions: Y.Z. and F.L. conceived and designed the experiments; Y.Z., F.M., Y.Z. and T.L. performed the experiments; Y.Z. and F.L. analyzed the data; R.C., S.L. Z.L. contributed reagents/materials/analysis tools; Y.Z., Z.Z. and F.L. wrote the paper.

Conflicts of Interest: The authors declare no conflict of interest.

\section{References}

1. Breslow, R.; Overman, L.E. Artificial enzyme combing a metal catalytic group and a hydrophobic binding cavity. J. Am. Chem. Soc. 1970, 92, 1075-1077. [CrossRef] [PubMed]

2. Wei, H.; Wang, E. Nanomaterials with enzyme-like characteristics (nanozymes): Next-generation artificial enzymes. Chem. Soc. Rev. 2013, 42, 6060-6093. [CrossRef] [PubMed]

3. Kuah, E.; Toh, S.; Yee, J.; Ma, Q.; Gao, Z. Enzyme mimics: Advances and applications. Chem. Eur. J. 2016, 22, 8404-8430. [CrossRef] [PubMed]

4. Wang, X.; Hu, Y.; Wei, H. Nanozymes in bionanotechnology: From sensing to therapeutics and beyond. Inorg. Chem. Front. 2016, 3, 41-60. [CrossRef]

5. Gao, L.; Zhuang, J.; Nie, L.; Zhang, J.; Zhang, Y.; Gu, N.; Wang, T.; Feng, J.; Yang, D.; Perrett, S.; et al. Intrinsic peroxidase-like activity of ferromagnetic nanoparticles. Nat. Nanotechnol. 2007, 2, 577-583. [CrossRef] [PubMed]

6. Lin, Y.; Ren, J.; Qu, X. Catalytically active nanomaterials: A promising candidate for artificial enzymes. Acc. Chem. Res. 2014, 47, 1097-1105. [CrossRef] [PubMed]

7. Gao, L.; Yan, X. Nanozymes: An emerging field bridging nanotechnology and biology. Sci. China Life Sci. 2016, 59, 400-402. [CrossRef] [PubMed]

8. Garg, B.; Bisht, T. Carbon nanodots as peroxidase nanozymes for biosensing. Molecules 2016, 21, $1653-1668$. [CrossRef] [PubMed]

9. Zhou, X.; Liang, F. Application of graphene/graphene oxide in biomedicine and biotechnology. Curr. Med. Chem. 2014, 21, 855-869. [CrossRef] [PubMed]

10. Sun, H.; Ren, J.; Qu, X. Carbon nanomaterials and DNA: From molecular recognition to applications. Acc. Chem. Res. 2016, 49, 461-470. [CrossRef] [PubMed]

11. Jariwala, D.; Sangwan, V.K.; Lauhon, L.J.; Marks, T.J.; Hersam, M.C. Carbon nanomaterials for electronics, optoelectronics, photovoltaics, and sensing. Chem. Soc. Rev. 2013, 42, 2824-2860. [CrossRef] [PubMed]

12. Maas, M. Carbon nanomaterials as antibacterial colloids. Materials 2016, 9, 617-635. [CrossRef] [PubMed]

13. Muňoz, J.; Baeza, M. Customized bio-functionalization of nanocomposite carbon paste electrodes for electrochemical sensing: A mini review. Electroanalysis 2017, 29, 1660-1669. [CrossRef]

14. Liu, H.; Zhang, L.; Yan, M.; Yu, J. Carbon nanostructures in biology and medicine. J. Mater. Chem. B 2017, 5, 6437-6450. [CrossRef] 
15. Navalon, S.; Herance, J.R.; Alvaro, M.; García, H. Covalently modified graphenes in catalysis, electrocatalysis and photoresponsive materials. Chem. Eur. J. 2017. [CrossRef] [PubMed]

16. Song, Y.; Qu, K.; Zhao, C.; Ren, J.; Qu, X. Graphene oxide: Intrinsic peroxidase catalytic activity and its application to glucose detection. Adv. Mater. 2010, 22, 2206-2210. [CrossRef] [PubMed]

17. Singh, S.; Mitra, K.; Shukla, A.; Singh, R.; Gundampati, R.K.; Misra, N.; Maiti, P.; Ray, B. Brominated graphene as mimetic peroxidase for sulfide ion recognition. Anal. Chem. 2017, 89, 783-791. [CrossRef] [PubMed]

18. Song, Y.; Qu, K.; Xu, C.; Ren, J.; Qu, X. Visual and quantitative detection of copper ions using magnetic silica nanoparticles clicked on multiwalled carbon nanotubes. Chem. Commun. 2010, 46, 6572-6574. [CrossRef] [PubMed]

19. Song, Y.; Wang, X.; Zhao, C.; Qu, K.; Ren, J.; Qu, X. Label-free colorimetric detection of single nucleotide polymorphism by using single-walled carbon nanotube intrinsic peroxidase-like activity. Chem. Eur. J. 2010, 16, 3617-3621. [CrossRef] [PubMed]

20. Shan, X.; Chai, L.; Ma, J.; Qian, Z.; Chen, J.; Feng, H. B-doped carbon quantum dots as a sensitive fluorescence probe for hydrogen peroxide and glucose detection. Analyst 2014, 139, 2322-2325. [CrossRef] [PubMed]

21. Shi, W.; Wang, Q.; Long, Y.; Cheng, Z.; Chen, S.; Zheng, H.; Huang, Y. Carbon nanodots as peroxidase mimetics and their applications to glucose detection. Chem. Commun. 2011, 47, 6695-6697. [CrossRef] [PubMed]

22. Wu, D.; Deng, X.; Huang, X.; Wang, K.; Liu, Q. Low-cost preparation of photoluminescent carbon nanodots and application as peroxidase mimetics in colorimetric detection of $\mathrm{H}_{2} \mathrm{O}_{2}$ and glucose. J. Nanosci. Nanotechnol. 2013, 13, 6611-6616. [CrossRef] [PubMed]

23. Luo, P.; Ji, Z.; Li, C.; Shi, G. Aryl-modified graphene quantum dots with enhanced photoluminescence and improved pH tolerance. Nanoscale 2013, 5, 7361-7367. [CrossRef] [PubMed]

24. Zheng, X.T.; Ananthanarayanan, A.; Luo, K.Q.; Chen, P. Glowing graphene quantum dots and carbon dots: Properties, syntheses, and biological applications. Small 2015, 11, 1620-1636. [CrossRef] [PubMed]

25. Wu, Z.L.; Liu, Z.X.; Yuan, Y.H. Carbon dots: Materials, synthesis, properties and approaches to long-wavelength and multicolor emission. J. Mater. Chem. B 2017, 5, 3794-3809. [CrossRef]

26. Sun, H.; Gao, N.; Dong, K.; Ren, J.; Qu, X. Graphene quantum dots-band-aids used for wound disinfection. ACS Nano 2014, 8, 6202-6210. [CrossRef] [PubMed]

27. Lin, L.; Song, X.; Chen, Y.; Rong, M.; Zhao, T.; Wang, Y.; Jiang, Y.; Chen, X. Intrinsic peroxidase-like catalytic activity of nitrogen-doped graphene quantum dots and their application in the colorimetric detection of $\mathrm{H}_{2} \mathrm{O}_{2}$ and glucose. Anal. Chim. Acta 2015, 869, 89-95. [CrossRef] [PubMed]

28. Zhou, Y.; Liu, L.; Shen, Y.; Wu, L.; Yu, L.; Liang, F.; Xi, J. Carbon dots promoted vanadium flow batteries for all-climate energy storage. Chem. Commun. 2017, 53, 7565-7568. [CrossRef] [PubMed]

29. Zhou, Y.; Yu, L.; Wang, J.; Liu, L.; Liang, F.; Xi, J. Rational use and reuse of Nafion 212 membrane in vanadium flow batteries. RSC Adv. 2017, 7, 19425-19433. [CrossRef]

30. Sun, H.; Zhao, A.; Gao, N.; Li, K.; Ren, J.; Qu, X. Deciphering a nanocarbon-based artificial peroxidase: Chemical identification of the catalytically active and substrate-binding sites on graphene quantum dots. Angew. Chem. Int. Ed. 2015, 54, 7176-7180. [CrossRef] [PubMed]

31. Wu, X.; Zhang, Y.; Han, T.; Wu, H.; Guo, S.; Zhang, J. Composite of graphene quantum dots and $\mathrm{Fe}_{3} \mathrm{O}_{4}$ nanoparticles: Peroxidase activity and application in phenolic compound removal. RSC Adv. 2014, 4, 3299-3305. [CrossRef]

32. Peng, J.; Gao, W.; Gupta, B.K.; Liu, Z.; Romero-Aburto, R.; Ge, L.; Song, L.; Alemany, L.B.; Zhan, X.; Gao, G.; et al. Graphene quantum dots derived from carbon fibers. Nano Lett. 2012, 12, 844-849. [CrossRef] [PubMed]

33. Yan, X.; Chen, J.; Yang, J.; Xue, Q.; Miele, P. Fabrication of free-standing, electrochemically active, and biocompatible graphene oxide-polyaniline and graphene-polyaniline hybrid papers. ACS Appl. Mater. Interfaces 2010, 2, 2521-2529. [CrossRef] [PubMed]

34. Wu, J.; Zhang, D.; Wang, Y.; Hou, B. Electrocatalytic activity of nitrogen-doped graphene synthesized via a one-pot hydrothermal process towards oxygen reduction reaction. J. Power Sources 2013, 227, 185-190. [CrossRef]

(C) 2017 by the authors. Licensee MDPI, Basel, Switzerland. This article is an open access article distributed under the terms and conditions of the Creative Commons Attribution (CC BY) license (http://creativecommons.org/licenses/by/4.0/). 